\title{
PSYCHOLOGICAL VARIABLES OF ESTIMATING DISTANCE LEARNERS' MOTIVATION
}

\author{
Dr. Ozlem CAKIR \\ Faculty of Educational Sciences \\ Ankara University \\ Ankara, Turkey \\ Tugra KARADEMIR \\ Faculty of Educational Sciences \\ Ankara University \\ Ankara, Turkey \\ Dr. Funda ERDOGDU \\ Faculty of Education \\ Dumlupınar University \\ Kutahya, Turkey
}

\section{ABSTRACT}

The correlation between distance education motivation levels of students and their online experiences and satisfaction is studied in this paper; and the reasons of their satisfaction and dissatisfaction according to their motivation levels are described. In this study, 183 students, who were taking English and Turkish courses at Ankara University between 20132014 academic year through distance education participated. The study which was designed in the form of sequential mixed method research design, "Motivation and Learning Strategies Inventory" and "Online Student Satisfaction Scale" were utilized to collect data and structured interview forms that were developed by the researchers and they were also used to determine students' online learning experiences and their satisfaction levels about distance education. Three motivation levels as low- medium-level- high were identified by clustering analysis. Logistic regression analysis was performed to evaluate motivation levels and satisfaction data and content analysis was applied to evaluate the reasons behind their satisfaction. A significant correlation was found between the students' motivation levels and their online learning experiences and satisfaction. When it comes to the reasons of their satisfaction and dissatisfaction, the students who have low and medium-level motivation levels said that their dissatisfaction was due to lack of interaction and negative perceptions and their dependence on conventional education. On the other hand, the students who have high motivation stated that their satisfaction was because it is free from time and space, suitable for reviews, provides effective learning and meets the requirements of this age. The students who were not satisfied in three different motivation levels mentioned the problems of internet access and lack of synchronization between the picture and the sound in the videos.

Keywords: Distance education motivation, online learning experience, distance education satisfaction, clustering analysis, logistic regression.

\section{INTRODUCTION}

The popularity of using technological tools in educational environments meets increasing educational demands and the need for lifelong learning. One of the educational environments, which provide equal opportunities for learners by using technological 
resources, is distance education systems. Learning can occur anywhere and anytime, even when and where students are apart from their instructor and peer students.

Online learning increases learners' ability to learn at their own convenience; however, the physical separation from their peers and instructors that online learning involves may result in a lack of communication and interaction and a weaker sense of belonging to a classroom community (Chaiprasurt and Esichaikul, 2013). These affect learners' motivation and can lead to poor performance, dissatisfaction and dropout (Balaban-Sali, 2008). The persistent online learner appears to need not only certain academic qualities and environmental support but also a high motivation level (Morris, Finnegan \& Wu, 2005).

Motivation is an essential factor to sustain learners' satisfaction in an online learning environment. Lack of motivation can be a major obstacle that prevents learners from concentrating on an instruction (Jeamu, Kim \& Lee, 2008). Lim (2001) had a total of 235 adults enrolled in Web-based distance education at five institutions complete questionnaires. She concluded that computer proficiency and self-efficacy had a positive effect on satisfaction and seemed to give learners increased confidence in the ability to handle the academic demands of distance education. The level of computer proficiency was found to be a significant factor affecting satisfaction and future participation in this distance learning format.

As mentioned in Kesim (2015), distance education systems that have increased rapidly all over the world make it easier to reach learners and reduce the cost of education; moreover, it provides opportunities to individualize the education of large masses. Cookson (1989) stated that the studies related to distance education were largely about the system infrastructure; however, the number of studies that examine the psychological and social conditions of students in distance education is not sufficient. Technically, distance education systems provide educational opportunities for larger groups of people but they must be structured considering every individual student. This situation requires restructuring the system considering the needs of each student as well as providing educational opportunities for larger groups of people. Therefore, it is necessary to enhance the technology of distance education systems and socio-psychological characteristics of each student have gained importance.

\section{Student Motivation in Distance Education}

One of the socio-psychological factors that affect students' enjoyment in education (Rattan, Good and Dweck, 2012) and their achievements (Giesbers, Rienties, Tempelaar, \& Gijeselaers, 2013) is motivation. Motivation is defined as the power that initiates, continues and changes behavior (Martin, 2001).

Studies that explore motivation to learn in online contexts are relatively limited in both number and scope (Artino, 2008). The studies that have been carried out so far have a tendency to adopt a limited view of motivation that does not acknowledge the complexity and dynamic interplay of factors underlying and influencing motivation to learn (Brophy, 2010).

Harandi (2015) found out that there is a significant relationship between students' completing a course and their motivation. Literature studies have shown that students with high motivation are less likely to leave a program (Keller and Suzuki, 2004). They have also reached the conclusion that the factors that enhance motivation in distance education increase students' attendance (Visser, 1998). Besides, the addition of the factors that increase motivation into distance education systems has caused a significant increase in students' course completion rates (Visser, Plomp, Amirault and Kuiper, 2002).

Moore and Kearsley (1996; Muilenburg \& Berge, 2005) stated that similar motivation problems are experienced in every distance education system and students with low motivation levels leave the program without completing or they feel isolated due to the lack of interaction. Dick, Carey and Carey (2005) have determined that learning cannot be achieved at an anticipated level if students' motivation is low. The motivation levels of each 
student in a learning environment can differ from each other. While some students finish the assignments on time, others finish them later or never do them (Cornell and Martin, 1997). Demographic characteristics of the students in distance education also differ from one another. Students in distance education can be individuals who have heterogeneous qualities such as living in different geographical locations, not being able to attend formal education institutions, being employed, being at different ages and having children. It is necessary to motivate such a target group in order to make them attend classes, become successful and complete the program. Therefore, we need well-designed distance education systems. Distance education systems must include a content, activities and interaction tools that can enhance a higher student motivation. Motivation is particularly significant in terms of personalization of the system and increasing the success through this system.

\section{Student Satisfaction in Distance Education}

There is a positive relationship between student satisfaction and the quality of teaching (Palmer and Holt, 2009). Five dimensions of online education are determined as educational effectiveness, cost effectiveness, accessibility, instructor and student satisfaction (Simsek, 2012). One of the most significant quality components of online learning is also described as satisfaction factor (Bourne and Moore, 2003). According to Ilgaz (2008), student satisfaction can be defined as the satisfaction resulting from learning-teaching activities and facilities. Satisfaction is seen as the variable that affects students' not only achievements but also their socio-psychological characteristics.

It is necessary to identify the satisfaction in order to determine the quality of online education programs (Yukselturk and Yıldırım, 2008) and improve students' learning (Sahin, Shelly, 2008). It is found that student satisfaction is positively correlated with interaction in online education (Moore and Kearsley, 1996). Moore and Kearsley (1996) mentioned three kinds of interaction in online education. These interaction patterns are student-student, student-content and student-teacher. Battalio (2007) examined various studies about online education and pointed out the significance of the student-teacher interaction pattern in those studies. Sahin (2007) conducted a study about student satisfaction in learning environments in online education and he concluded that having effective assistance and feedback from the instructor on time and being able to communicate with the instructors easily increase their satisfaction. The studies that have been conducted so far described the factors that affect student satisfaction in online education. They are self-efficacy (Liaw, 2008), interaction among learners and characteristics of learners (Hong, 2002), the quality of course content and material, student-student and student-teacher interaction patterns (Wagner, Wemer and Schramm, 2002) and demographic qualities (Karatas and Ustundag, 2008). Soon, Sook, Jung and Im (2000) found out in their study in which they examined satisfaction about web-based courses that response and feedback given to students' questions and tasks on time positively correlates with student satisfaction. In addition to this, it can be seen that there is a positive interrelation among satisfaction, computer literacy, internet access (Cakir, 2014), and computer experience (Sahin and Shelly, 2008). Completing online activities and tasks successfully is described as the students' internet selfefficacy (Eastin and LaRose, 2000). Students with high internet self-efficacy are able to use interaction tools necessary for online courses, communicate with classmates or teacher and participate in discussions and group works. A positive correlation was found between students' satisfaction and their internet self-efficacy (Chu and Chu, 2010).

Bouhnik and Marcus (2006) described the reasons for student dissatisfaction in distance education as the lack of an effective framework that can encourage students to learn, not having a learning environment in distance education systems as well as the requirement of self-discipline. Besides, not having a direct student-student and student-teacher interaction requires more time for learning compared to face-to-face learning. Gaddis, Napierkowsk, Guzman and Muth (2000), Kitchen and McDougal (1988) described other reasons as uncertainty of teacher expectations, inflexible timetable, work overload, a badly designed user interface, slow internet connection and not having simultaneous communication. 
Online Experience in Distance Education

Another factor that is likely to affect distance education is students' online experiences. Users with high computer experience participate in web-based learning more willingly (Mitchell, Chen, McCredie, 2005). Hannafin and Cole (1983) stated that the individuals who developed positive approach to computer have higher satisfaction levels. Using information technologies in personal and professional life enables students to utilize online tools more comfortably. Having computer experience and technical support improves student's learning (Jones, Packham, Miller and Jones, 2004). If students lack self-confidence about information technologies, they have less experience about technology (Liaw, 2008).

In distance education, students need to have basic computer skills to control their own learning (Sahin and Shelley, 2008). Besides, negative experiences that students get from online courses are among the reasons why they leave the system (Jaggards, 2014). Negative experiences in online environments resulted from technical problems (Bambara, Harbour, Davies \& Athey, 2009) and students and educators' declining sense of being there (Bambara, et al. 2009; El Mansour and Mupinga, 2007) or having problems about self-learning and time management (Bork and Rucks-Ahidiana, 2013). According to Kaupp (2012), performing poorly in online courses compared to face-to-face courses can be the reason for this difficulty. Starting from this point of view, we can say that the success of a system depends on its feasibility. Therefore, those who have less online experiences can find it hard to learn distance education tools and they may not be motivated in participating online activities (Xie, Debacker and Ferguson, 2006).

In online education, while using information and communication technologies, thinking that they are going to perform badly and having a low self-esteem affect students' satisfaction negatively (Kuo, Walker, Belland and Schroder, 2013). Arbaugh (2000) found a positive correlation between students' learning experience and their satisfaction about web-based distance education.

Relationship among Multi Psychological Variables that Affect Distance Education Muilenburg and Berge (2005) stated that motivation factor is very important in completing distance education programs. According to Kransow (2013), learners who are satisfied with their online experiences stay longer in distance education programs; however, those who leave the program are determined to have low satisfaction. Althaus (1997) has mentioned that students who have more computer experience are better at using interaction tools and concluded that they find using these tools more useful. As a result, studies have proved that three variables such as motivation, online experience and satisfaction are effective distinctively in a good distance education system. Although there are studies that reveal each variable's effect on distance education, any studies that present these variables' impact on each other and the reasons for this impact have not been detected in the literature.

Introducing multiple effects of the psychological factors that are effective in the structure of distance education rather than introducing their single effect is important in terms of determining psychological factors that need consideration in setting up distance education systems in the future. A good system is designed considering more than one factor and based on the power of their effects. In a well-designed distance education system, revealing the impact of interrelated variables on each other can cause an increase and a decrease in more than one variable by small changes.

In the study in which there is a correlation between motivation and online experience, and between motivation and student satisfaction, it will be suggested that a change only intended to increase motivation will also affect online experience and satisfaction. More than one variable affects learning. Showing that those variables are interrelated is important. It is significant to introduce the interrelation among psychological factors to be able to design a well-structured distance education and to enhance the expansion and sustainability of the quality of education. From this point of view, we tried to reveal the relationship among 
psychological variables that affect distance education by using quantitative and qualitative data. In literature, the most important three factors that can cause individuals to leave the program are the lack of motivation, satisfaction and online experience.

In this study, the purpose is to reveal underlying reasons thematically by determining the relationship between students' motivation levels, satisfaction and online experience. The data obtained will provide resource for academicians and practitioners to form the system and develop learning environments, content and materials. In accordance with this purpose, sub goals that need answers are given below:

For the students in distance education;

$>$ Is there a significant relationship between online experience and motivation?

$>$ Is their satisfaction a significant predictor for their motivation levels?

$>$ What are the underlying effects of the relationship between their motivation levels about distance education and satisfaction?

This study is limited with 183 students who took Turkish and English courses in distance education in 2013 and 2014 academic years.

\section{METHOD}

Exploratory sequential mixed research design was used as a mixed method in the study. Exploratory sequential mixed design is a study in which quantitative data in the first stage and quantitative data in the second stage are collected (Creswell, 2013). The design of this research was given in Figure 1.

The Sample, their characteristics and their selection methods are described in detail and justified.

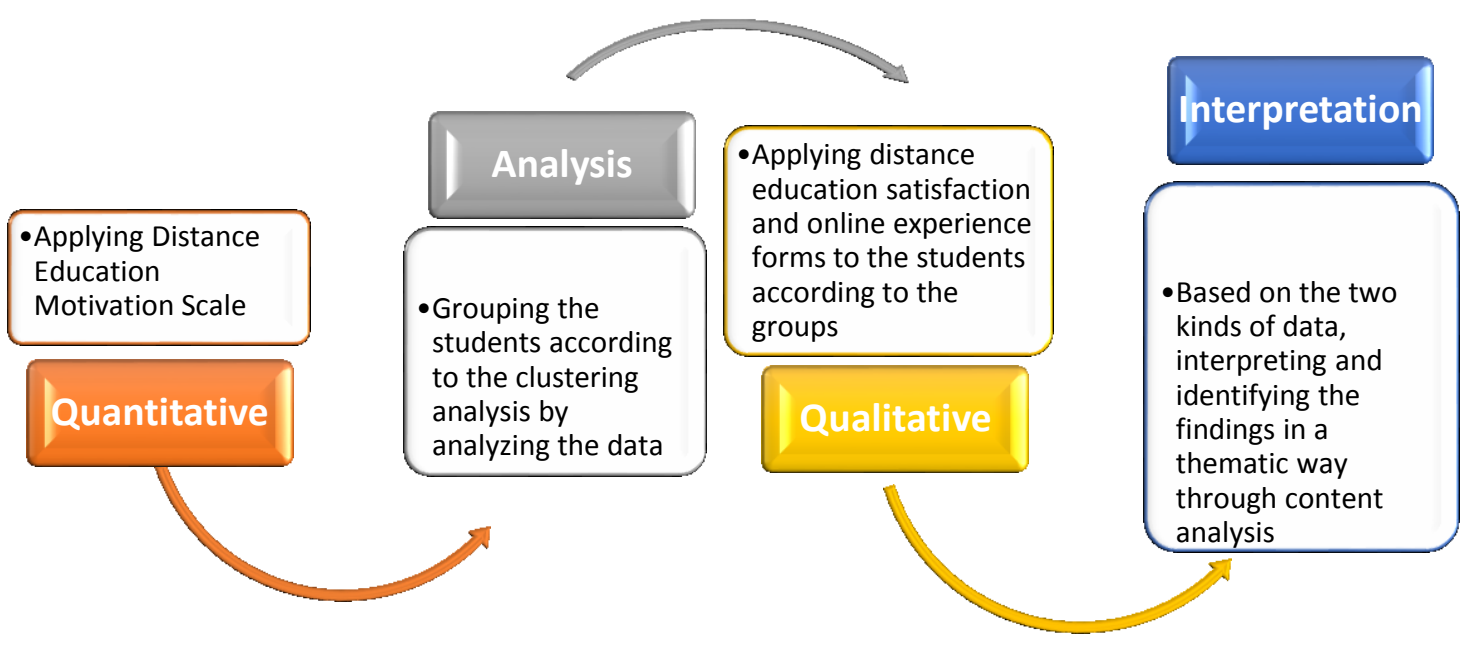

Figure 1. The research design 


\section{Participants}

The study group of the research is formed with 183 prospective teachers who were taking English and Turkish courses in distance education program in the Faculty of Educational Sciences, Ankara University in 2013-2014 Fall and Spring terms. The $25.1 \%(n=46)$ of prospective teachers who participated in the study are in the department of primary school teaching. The $19.1(n=35)$ of them are in the department of computer education and instructional technologies. The $18.6 \%(n=34)$ are in the department of psychological counseling and guidance, $16.9 \%(n=31)$ of them are in the department of preschool teaching, $14.2 \%(n=26)$ are in the department of social sciences teaching and $6 \%(n=11)$ of them are in the department of teaching of mentally disabled.

\section{Data Collection}

Assessment instruments that were used to collect data in the study were mentioned below.

\section{Motivation Strategies and Learning Questionnaire (MSLQ)}

In the study, MSLQ was used with the purpose of collecting data to determine the students' motivation levels about distance education. MSLQ, which was developed by Pintrich, Smith, Garcia and Mckeachie, was adapted into Turkish by Buyukozturk, Akgun, Ozkahveci and Demirel (2004). The scale is composed of six factors including intrinsic goal orientation, extrinsic goal orientation, task value, control of learning beliefs, self-efficacy for learning, performance, test anxiety and 31 items in total. The scale is in the type of 7-point Likert scale ranging from not at all true of me (1) to very true of me (7). Cronbach Alpha values of adapted Turkish version of the scale range from 0.52 to 0.86 . According to the information collected from English and Turkish forms of the scale, correlation coefficient of total score is 0.85 .

\section{Online Learners' Satisfaction Scale}

Online Learners' Satisfaction Scale, which was developed by Cakır (2012) to determine students' satisfaction levels, was used in this research. The scale was composed of 38 items ranging from I totally disagree (1) to I totally agree (7) in the type of 7-Likert scale. It has three factors including the structure and the process of the program, interaction with the instructor and interacting with other students. It explains the $\mathbf{6 7 . 9 5}$ of the total variance and the scale is reliable and valid as its coefficient of internal consistency is 0.97 , which was measured by Cronbach Alpha.

\section{Form of Distance Education Satisfaction and Online Course Experiences}

This form was developed by the researchers to find out the reasons underlying students' satisfaction about distance education and their online course experiences. The researchers have PhD in the field of Educational Technology. They designed forms in accordance with the purpose of the study and the forms were finalized based on the opinions and suggestions of the researchers.

The form has two sections. There are open-ended questions in the first section so that students can express themselves comfortably. The questions were prepared without guidance based on the guidelines of qualitative interview. Some of the questions were given below:

What are the benefits of distance education?

$>$ What are your opinions about taking different courses in distance education?

$>$ What are the difficulties you face while taking a distance education course?

$>$ What are the dissatisfying points of distance education?

$>$ What are your thoughts about using distance education at university level?

In the second part of the form, there are twelve survey questions to measure their experiences. There are question items under the topics such as file operations, digital evaluation instruments, use of interactive environments, technical infrastructure and dealing with the problems. The scores obtained from the surveys were used to determine the significance of students' online experiences. 
Data Analysis

The students were grouped by performing clustering analysis of the average scores collected from the first scale used at the beginning of data analysis. The results of the clustering analysis were given in the findings section. Chi-square analysis was applied to determine the relationship between motivation levels and online experiences. Logistic regression analysis was used to present the predictability of motivation level and satisfaction. Based on the results of logistic regression analysis, a significant correlation was found between students' motivation levels and their satisfaction about distance education. The analysis about the interview form is performed in qualitative dimension. Computer-based qualitative data analysis was done. NVivo program was used to analyze the data. The coding was formed in accordance with the common views of three researchers.

Content analysis was utilized for an in-depth analysis of the reasons underlying this correlation. Two types of coding were used to analyze the qualitative data. In the first cycle of coding, open coding and in vivo coding were employed. During the second cycle of coding, the topics were finalized by using axial coding. After the coding, with the help of two domain experts, necessary adjustments were made for the consistency of the topics. Thematic explanations of the reasons for distance education satisfaction were compared, contrasted based on the students' levels of motivation, and displayed in the findings section.

The reliability of content analysis specifically depends on the coding process. One of the most significant properties of the categories is having the clarity so that another researcher who uses the same document for the same purpose has to reach almost the same conclusions (Tavsancll and Aslan, 2001). Therefore, interpretation of the categories cannot differ from one researcher to another or in different times. In this context, the reliability of the coding was examined to determine how reliable the programmer was while coding the categories. With this purpose, the data collected within the scope of the research were designed and coded separately by two researchers. Coded data were examined and grouped based on their similarities and differences. Related codes were brought together to form themes. In this process, the codes that have difference of opinion and agreement are spotted and the consistency between the coders was examined. The value of reliability (Cronbach alpha) between coders was found to be as $\mathbf{0 . 9 2}$. Concordance rate, which is used to determine interrater reliability and in reliability, is expected to be higher than $70 \%$ (Tavsancil and Aslan, 2001: 81). Having a result over this rate indicates that the reliability between coders is in a sufficient level.

\section{FINDINGS}

\section{Determining Student Groups by Clustering Analysis}

The data collected from motivation scale of distance education were analyzed by clustering analysis based on total scores. The number of people per group and each individual in each cluster were presented according to cluster analysis. The three groups formed because of cluster analysis and the Ward table related to the groups where some of the students took part in was given below.

Table 1. Cluster memberships gained through ward's connection (the smallest variance) method

\begin{tabular}{|c|c|c|c|c|c|c|c|c|c|c|c|}
\hline $\begin{array}{l}\text { Student's } \\
\text { Code }\end{array}$ & Cluster & $\begin{array}{l}\text { Student's } \\
\text { Code }\end{array}$ & Cluster & $\begin{array}{l}\text { Student's } \\
\text { Code }\end{array}$ & Cluster & $\begin{array}{l}\text { Student's } \\
\text { Code }\end{array}$ & Cluster & $\begin{array}{l}\text { Student's } \\
\text { Code }\end{array}$ & Cluster & $\begin{array}{l}\text { Student's } \\
\text { Code }\end{array}$ & Cluster \\
\hline P11 & 1 & P98 & 2 & P132 & 3 & P82 & 2 & P18 & 2 & P57 & 2 \\
\hline P127 & 2 & P134 & 3 & P156 & 3 & P107 & 3 & P38 & 2 & P114 & 3 \\
\hline P48 & 2 & P183 & 3 & P184 & 3 & P159 & 3 & P96 & 2 & P78 & 2 \\
\hline P49 & 2 & P187 & 3 & P188 & 3 & P175 & 3 & P108 & 3 & P79 & 2 \\
\hline P61 & 2 & P9 & 1 & P19 & 2 & P5 & 1 & P119 & 3 & P81 & 2 \\
\hline P179 & 3 & P87 & 2 & P53 & 2 & P1 & 1 & P45 & 2 & P4 & 1 \\
\hline P14 & 2 & P103 & 3 & P59 & 2 & P2 & 1 & P63 & 2 & P69 & 2 \\
\hline P42 & 2 & P109 & 3 & P64 & 2 & P3 & 1 & P102 & 2 & P111 & 3 \\
\hline
\end{tabular}


In Table 1, when the cluster membership gained through Ward's Connection Method is examined, it can be seen that there are 12 students in the first cluster, 90 in the second and 81 students in the third cluster. When the highest and lowest levels of average scores of the students who took part in groups are examined, it can be seen that the average scores of the students in the first group are valued between 81-and 152; second group's scores are between 263-357 and third group between 361 and 520. From this point of view, the first group is called as low-level motivation (LM), the second group is medium-level motivation (MM) and the third group is called as high-level motivation (HM). As a result, the students were put into three groups and following analysis were done based on this grouping.

\section{Chi-square Test Results Regarding Motivation Levels of Students about Distance Education According to Their Online Experiences}

Students were classified into two categories as high and low according to their online experiences considering the answers they gave to the questions of the survey existed in the second part of the form of distance education satisfaction and online course experiences. Therefore, the results of chi-square test to measure the relationship between the students' motivation levels and online experiences were given in Table 2.

Table 2. Chi-square test results about the students' motivation levels of distance education according to their online experiences

\begin{tabular}{|c|c|c|c|c|}
\hline \multirow[t]{2}{*}{ Levels of Online Experiences } & \multicolumn{4}{|c|}{ Motivation Levels of Distance Education Total } \\
\hline & LM & MM & HM & \\
\hline High n & 1 & 60 & 71 & 132 \\
\hline Low n & 11 & 30 & 10 & 51 \\
\hline Total & 12 & 90 & 81 & 183 \\
\hline
\end{tabular}

According to chi-square analysis result, a significant relationship between the motivation levels of distance education and online experience levels is determined $[\times 2(6)=30,82$, $\mathrm{p}<.05]$. When Table 2 is examined, it is discovered that the students who have a high level of online experience are mostly $(n=71)$ in HM category, the least $(n=1)$ is in LM category. Those who have low levels of online experience are mostly $(n=30)$ in MM (medium level motivation) and the least $(n=10)$ is in HM category. Because the difference between the groups is significant, it means that the students' online experience levels affect their motivation significantly.

Logistic Regression Results of the Students' Satisfaction about Distance Education and Motivation Categories

Logistic regression analysis was performed to determine students' state of satisfaction about distance education as the second sub-problem of the research and to find out whether it is a significant predictor of their motivation levels. First, the problem of multicollinearity among the variables was examined. Eigen values, condition indices and variance proportions related to the examination of the problem of multicollinearity among the variables used in logistic regression analysis were given in Table 3; standard errors, tolerance and VIF values about predictor variables and bivariate correlation values among the variables were given in Table 4. 
Table 3. The examination of multicollinearity problem among predictor variables through eigenvalue, condition index and variance proportions

\begin{tabular}{ccccc}
\hline & & \multicolumn{3}{r}{ Variance Proportions } \\
\multicolumn{2}{c}{ Eigenvalue } & CI & \multicolumn{2}{c}{ Constant } \\
\hline 1 & 1,969 & 1,000 &, 02 &, 02 \\
2 &, 031 & 7,983 &, 98 &, 98 \\
\hline
\end{tabular}

When Table 3 is examined, it can be seen that eigenvalues of all predictor variables show similarity. According to Gujarati (1995), it shows a multicollinearity problem in "high level" if $\mathrm{CI}$ value is bigger than $\mathbf{3 0}$ and if it is ranges from $\mathbf{1 0}$ to 30, it shows a "medium-level" multicollinearity problem. The $\mathrm{CI}$ value of the variables in the study was found as 7,983 . This means that condition index values (CI) are in the desired ranges.

Table 4. The examination of multicollinearity problem among predictor variables through standard error, tolerance and VIF values

\begin{tabular}{cccccc}
\hline Predictor Variables & $\mathrm{B}$ & Standart Error & Tolerance & VIF & Correlation \\
\hline Motivation & -.079 & -.059 & 1.065 & 1.055 & .099 \\
\hline $\mathrm{p}<.01$ & & & & &
\end{tabular}

When the VIF values of the variables were examined, it was found out that the value is 1.055 and it is smaller than 10. In the field of literature, if the value of tolerance is bigger than 1, it shows that there is not multicollinearity problem among the variables (Field, 2005; Mertler and Vannatta, 2005). When the tolerance values were examined in Table 4, it was found out that tolerance values about all the variables are bigger than 1. It can be interpreted that the ones with correlation values between 0 and .30 show low correlation, those with values between .31 and .70 is medium and the ones with values between .71 and 1 show high correlation (Buyukozturk, 2009). The correlation of the variables in the study has a low correlation with a value of .099. When the Table 3 and 4 were examined, it is seen that there is not multicollinearity among the variables.

Table 5. Omnibus test about model coefficient

\begin{tabular}{llll}
\hline & Chi-Square & df & p \\
\hline Step & 23,907 & 1 &, 000 \\
\hline Block & 23,907 & 1 &, 000 \\
\hline Model & 23,907 & 1 &, 000 \\
\hline
\end{tabular}

Omnibus values about model coefficients of the variables were given in Table 5. When Table 5 is examined, it is seen that chi-square value of the model is " $p<.05$ ". Because "p" value is found significant, it shows that a correlation exists between dependent and independent variables. Therefore, it can be said that there is a correlation between the students' state of satisfaction of distance education and their motivation levels.

Table 6. The summary of targeted model

\begin{tabular}{llll}
\hline Step & -2 LL & Cox and Snell R2 & Nagelkerke R2 \\
\hline 1 & $225,787 a$ &, 122 &, 164 \\
\hline
\end{tabular}

Table 6 is examined, Cox, Snell R2 and Nagelkerke R2 values represent that explained variance in dependent variable by the model is affected by two different ways. This means that the students' online experience explains $12.2 \%$ of the variance in the predicted variable of the motivation for distance education. 
Table 7. Hosmer and Lemeshow test

\begin{tabular}{cccc}
\hline \multicolumn{4}{c}{ Chi-Square } \\
Step & & df & p \\
\hline 1 & $\mathbf{1 , 2 8 8}$ & $\mathbf{1}, \mathbf{2 5 6}$ \\
\hline
\end{tabular}

When Table 7 is examined, it is evident that Hosmer and Lemeshow tests are not significant $(p=.256>.005)$. The fact that these tests are not significant shows that the model with two variables has a satisfactory consistency, in other words, the consistency of model and data is in an efficient level. Thus, it is seen that the correlation between the students' state of satisfaction about distance education and their motivation levels is significant.

In Table 8, the categorization as a result of logistic regression model was presented. This table is the application of regression model to predict group memberships.

Table 8. Categorization table

\begin{tabular}{|c|c|c|c|c|}
\hline \multirow{3}{*}{ Observed } & & \multicolumn{2}{|c|}{ Expected outcome } & \multirow{3}{*}{$\begin{array}{l}\text { Percentage of correct } \\
\text { classification }\end{array}$} \\
\hline & & \multicolumn{2}{|c|}{ Being satisfied with distant education } & \\
\hline & & Satisfied & Dissatisfied & \\
\hline \multirow{2}{*}{$\begin{array}{l}\text { Being satisfied with } \\
\text { distant education }\end{array}$} & Satisfied & 60 & 45 & 57,1 \\
\hline & Dissatisfied & 21 & 57 & 73,1 \\
\hline $\begin{array}{l}\text { First classification } \\
\text { percentage }\end{array}$ & \multicolumn{2}{|c|}{$57.4 \%$} & $\begin{array}{l}\text { The classification percentage } \\
\text { after variables added into the } \\
\text { model }\end{array}$ & $63.9 \%$ \\
\hline
\end{tabular}

When the categorization formed by logistic regression model is examined, it is seen that total correct categorization is $\mathbf{6 3 . 9} \%$. This value is $\mathbf{5 7 . 4} \%$ in the first categorization. These findings show that model-data consistency is in an efficient level. This means that the state of whether the students are satisfied with distance education or not can be categorized by looking at their motivation scores.

Table 9. Coefficient predictions of targeted model variables

\begin{tabular}{|c|c|c|c|c|c|c|}
\hline & $\boldsymbol{\beta}$ & Standard Error & Wald & df & $\mathbf{p}$ & $\operatorname{Exp}(B)$ \\
\hline Motivation Levels for Distance Education & $-1,292$ & 284 & 20,700 & 1 & ,000 & ,275 \\
\hline Constant & 2,743 & ,682 & 16,178 & 1 & ,000 & 15,531 \\
\hline
\end{tabular}

When Table 9 is examined, it is seen that one unit increase in predictor variable of motivation levels for distance education results in $72.2 \%[(1-0,275) * 100$ decrease in the odd of their state of dissatisfaction about distance education. The reason why it causes a decrease is its coefficient has a negative sign. In other words, when there is a unit of increase in students' motivation, there will be a $\mathbf{7 2 . 2} \%$ decrease in their state of dissatisfaction. When all the data collected were examined, it is concluded that students' state of satisfaction is a significant predictor of their motivation. The reasons of this finding were revealed after structured interviews, which were collected qualitative data.

\section{Thematic Presentation of Students' Satisfaction Indicators}

The themes obtained through structured interview forms, which were used with the purpose of an in-depth understanding of the reasons underlying the attitude of satisfaction and dissatisfaction about distance education, were presented in Figure 2. 


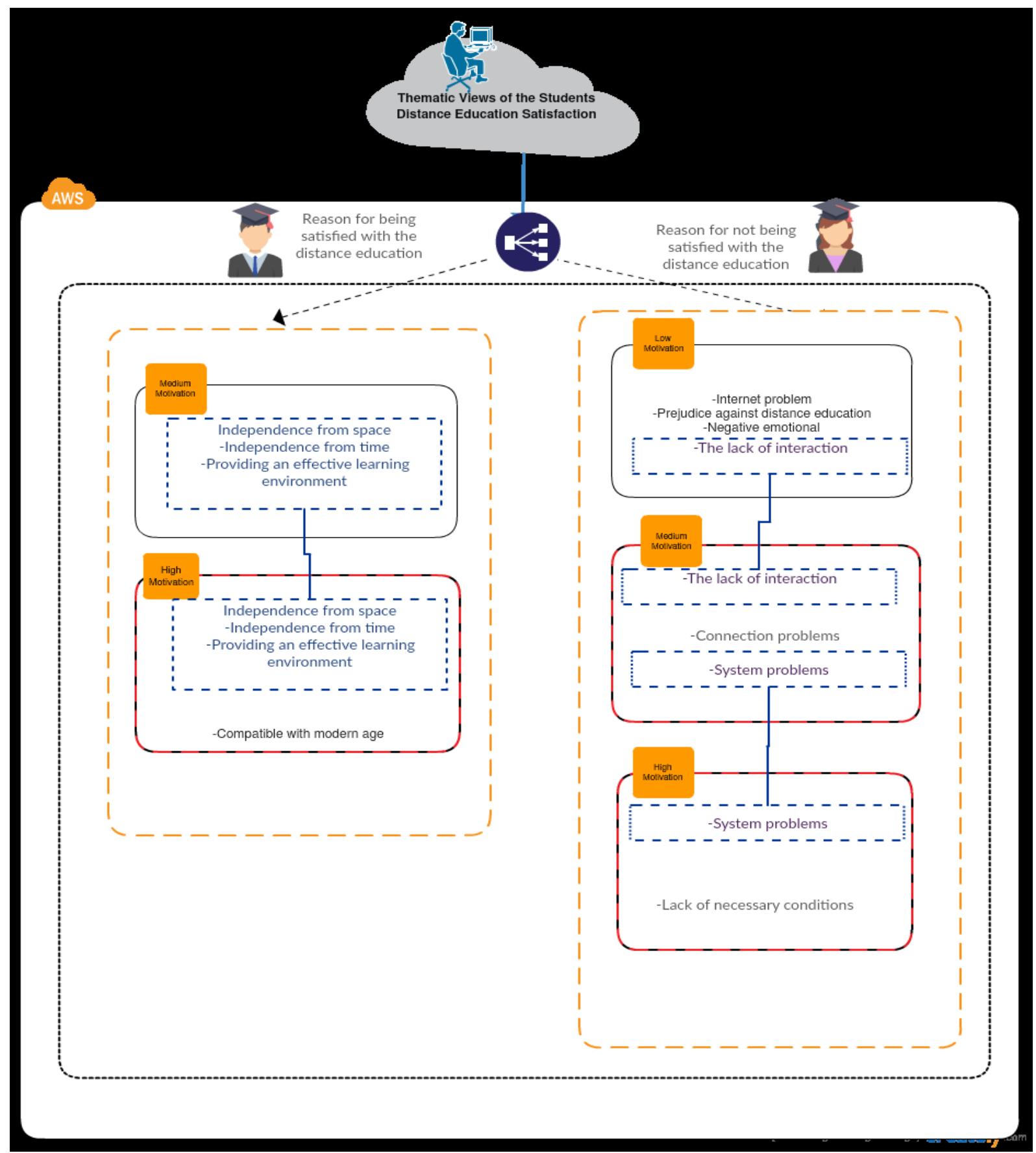

Figure 2. The themes obtained through structured interview forms

When Figure 2 is examined, it is seen that the reasons of students' satisfaction about distance education show difference according to their motivation levels. When the findings were examined, it was concluded that $97 \%$ of LM students were not satisfied with distance education but $3 \%$ of them were satisfied with distance education. LM students usually stated that they were not satisfied because of internet connection problems.

"...Internet access is a problem for me. I do not have a continuous internet connection."

Besides the problems of internet connection, it is seen that the lack of interaction with instructors and students affect their state of satisfaction negatively. 
"... I like face-to-face contact with the instructor", That is why I cannot understand the lecture without seeing the teacher...", Teacher and student must be in the same environment, if the lecture is carried out in a class, $I$ am sure the success rate will increase. When we do not understand something here, the instructor finishes the subject until we write our question. When $s /$ he sees our question, $s /$ he responses back but it becomes confusing for us. Distance education must be ended."

Besides, it is seen that prejudgments of the students about distance education affect their state of satisfaction negatively. This prejudgment affects the efficiency of the courses in distance education.

\section{"I BELIEVE THAT MY SUCCESS WILL FALL IN DISTANCE EDUCATION.", "Distance education is not as effective as formal education...", "distance education is not a healthy environment for lectures", "... it is not educational."}

Finally, the students who have low motivation mentioned that it has an impact of negative affective as one of the reasons of their dissatisfaction. They said that distance education distracts attention and change motivation and attitude in a negative way.

"I think it does not provide motivation for the courses and that is why it is not efficient", "I think it is not efficient because my attention can be distracted easily while $I$ am online so concentrating on the course is impossible."

The students with low motivation have not expressed any opinions about the reasons why they are satisfied.

While $46 \%$ of MM students stated that they were satisfied with distance education, $44 \%$ of them said they were dissatisfied. The reasons of their satisfaction and dissatisfaction were given below. The students who have medium-level motivation (MM) said that they were most dissatisfied with distance education because of the problems of internet connection like LM students.

"Internet access is a problem for me. I do not have an constant internet connection", "I am not happy because I find it difficult to understand the lecture due to a lack of communication." "...my internet accessibility is not easy enough...", "internet access mostly causes problems."

Besides, just like LM students, MM students also mentioned that lack of interaction with instructor and other students were the reasons underlying their state of dissatisfaction about distance education.

"... because I cannot communicate effectively". "... because I cannot communicate with the instructor effectively. For example, as I was writing the question, the instructor might finish that topic and start a new one," "attending lectures is more difficult."

Another reason of MM students' state of dissatisfaction about distance education is their dependence on conventional classes. They think that education in conventional classes is more effective than distance education.

"...learning rate falls as it is not an effective classroom environment." "It is not like face-to-face education. I cannot feel an atmosphere of a lecture.", "BECAUSE CARRING OUT THESE COURSES IN A FORMAL EDUCATION 
SETTING IS MORE BENEFICIAL FOR OUR LEARNING.", "I believe education must take place in a class face-to-face with a teacher."

MM students also said that they experience some problems with the system. These problems were stated as the problems of sound, picture quality and downloading videos properly.

"There are some problems in the system.", "it is difficult to watch the videos on the computer", "as I watch the lecture later, recorded videos do not generally open, and when they open, the sound and the picture are not synchronized", "...the picture quality is very low..."

When the reasons of MM students' state of satisfaction are examined, it is seen that the first reason is that distance education is free from time and space. That students can watch the lectures whenever or wherever they want and have the chance of repeating it lead up to their satisfaction about distance education.

"...because listening to a lecture in the comfort of my home is very relaxing", "we can easily access to the lecture at home or on the way", "Attendance is not a problem.", "IT IS VERY COMFORTABLE IN TERMS OF USING THE TIME", "...I can have the opportunity to watch the lectures whenever I want. If I miss a point, I can go back and listen to it again."

Moreover, MM students say that distance education systems make learning easier by providing effective learning environments.

"I fit into distance education in terms of content and $I$ do not need conventional education.", "I find it very useful to be able to use the media at home and we can learn the lectures efficiently."

The $74 \%$ of HM students stated that they were satisfied with distance education and $26 \%$ of them said they were not satisfied. The students stated system problems as the first reason of their dissatisfaction. These problems were attributed to slow connection, inefficient technology and the problems of sound and picture.

"As I cannot access the system easily...", "when I watch the video later, the sound and the picture are not synchronized.", "Technology is inefficient because of lack of communication.", "...it is difficult to access the courses and watch the lectures.", "There are always some problems in the system."

Besides, students mentioned the lack of facilities like having internet connection or a computer as the reasons of their dissatisfaction.

"...because it is very difficult for me to access the internet.", "I do not have a possibility of accessing the system all the time and because of this reason I am not happy.", "I do not have a computer."

Similarly, just like LM students, HM students expressed their satisfaction about distance education in terms of being free from time and space. Accessing the courses whenever and wherever they want and the opportunity of repeating the courses are the topics that the students are most content.

"We do not have to attend the courses, we can access the courses wherever we want.", "Saving time, space and labor...", "I am happy because I can be home and save time...", "I am happy because I can access the courses wherever a computer exists and I can watch whenever I want..." 
Another reason of HM students' satisfaction is that distance education provides an effective learning environment. Having the chance of repeating the lectures in the system whenever they want and watching the videos affect their satisfaction.

"We can listen and revise our lectures easily and comfortably.", "...the lectures go well and efficient/y...", "I can watch the lecture again whenever I want...", "... we have a chance of watching the videos and listening to the lecture out of the class hour."

Furthermore, HM students said that they were pleased with distance education because it fits the requirements of the age.

\begin{abstract}
"as university students, distance education system in a technological age can make us more successful in our educational lives.", "because it is suitable for this information age...", "Having education without going to a university is very comfortable and it is up to date."
\end{abstract}

\title{
DISCUSSIONS AND CONCLUSION
}

Distance education offer opportunities independent from time and place to individuals who have to quit school or cannot have education for various reasons. Besides, distance education makes it possible to offer educational opportunities to larger masses more economically by using technology to provide equality in opportunities. The success of distance education systems offered to the individuals is affected by technical infrastructure, pedagogy and psychological factors.

In this study, it is tried to reveal the interrelation between motivation, online experience and satisfaction and the reasons underlying this relationship. Within this scope, firstly, students' motivation towards the system is analyzed in three categories as high, medium and low through cluster analysis based on the scores obtained from Distance Education Motivation Scale. It is concluded that students' online experience is a meaningful predictor in three levels of their distance education motivation. Those who have high online experience cluster in medium and high motivation whereas those who have low online experience cluster in medium and low motivation. It is found out that computer skills is important in adapting to the distance education more easily and developing a positive attitude towards distance education (Chang and Tung, 2008; Brinkerhoff and Koroghlanian, 2005; Drennan, Kennedy, and Pisarsky, 2005). It is suggested that before the program begins, a training program about online environment and tools be given to students who have weaker computer skills in order to encourage them to attend courses and use interaction tools (Sahin and Shelly, 2008).

Another finding of the study is that students' satisfaction is a meaningful predictor in three levels of their motivation. Those who have high motivation are satisfied with distance education while the ones with low motivation are dissatisfied with distance education. When considered from this aspect, it should not be forgotten that their satisfaction would affect their motivation while structuring distance education systems.

At the end of the interviews carried out with the purpose of discovering the underlying reasons of the relationship between students' motivation and their satisfaction levels, students' satisfaction and dissatisfaction were classified based on their motivation levels.

The reasons for students' satisfaction about distance education differ based on their motivation levels. Students with high motivation mentioned various reasons for their satisfaction about distance education. They frequently mention that they are satisfied because they can use their own time, at a place of their own choice and it provides effective learning environment and is suitable for the necessities of the time. Those who have medium motivation stated that they are satisfied with distance education because they feel free about time and place and it provides effective learning environment. The students with low 
motivation did not state any opinion about their satisfaction. In the study conducted by Belcheir and Cucek (2002), students stated that they are satisfied with distance education because they feel independent about time and place as stated in this study. While the students with high and medium motivation are satisfied with distance education because it has the quality of being independent of time and place, it is determined that this quality does not have any impact on the satisfaction of those with low motivation. This finding can be interpreted that the students with low motivation have a negative perception about distance education.

The students with high and medium motivation are alike in their satisfaction about distance education as it is independent of time and place and it provides effective learning environment; however, those with high motivation emphasized the suitability to the requirements of the time. This emphasis of the students with high motivation might result because of being innovative and following the latest technological developments. Besides, the students with high motivation could be individuals who are more familiar with the popular culture. When it is considered from this point, it is necessary to do an in-depth examination of the differences about their social conditions to emphasize underlying reasons for this difference. In a study conducted by Sun and Tsai, Finger, Chend ve Yeha (2008) satisfaction factors are examined under six headings. These are learner (learner's attitude, anxiety and perception of self-efficacy towards distance education), teacher (teacher's feedback speed and attitude towards distance education), course (the quality and flexibility of the course), technology (the quality of technology and the internet), design (perceived usability and user-friendliness) and finally environmental factors (diversity of evaluation and learner's perception of interaction with others). In addition to factors determined in the study by Sun, Tsai, Finger, Chend and Yeha (2008) students' satisfaction is described by categorizing their motivation levels.

When we examine students' dissatisfaction based on their motivation levels, it was stated that students with low motivation have a difficulty in accessing the internet and they have bias and negative affectivity. While students with medium motivation mentioned connection problems, lack of interaction, dependence on conventional education and system problems as the reasons for their dissatisfaction, the students with high motivation identified them as system problems. The students with low and medium motivation mentioned both technical and psychological factors, whereas those with high motivation only described technical problems. Within this context, it can be seen that the students with low and medium motivation have bias against distance education and are dependent on face-to-face education. Moreover, the lack of interaction was emphasized in both levels. A significant correlation was found between satisfaction and interaction in some other studies (Strachota, 2003; Swan, 2001). In a study carried out by Garrison (1990), it is concluded that students are more motivated in a distance education system where there is a regular student-student, student-teacher interaction. When considered from this aspect, it is thought that if interaction increases, satisfaction and motivation levels naturally rise. Gaddis, Napierkowsk, Guzman and Muth (2000) described the reasons of dissatisfaction as uncertain expectations of educators, inflexibility of the courses, work overload, bad interface design, slow connection and the lack of simultaneous communication. On the other hand, Bouhnik and Marcus (2006) mentioned reasons such as the lack of program that encourages students to learn, students' need for self-discipline, not having a learning environment, not having a direct student-student and student-teacher interaction and needing more time to learn compared to face-to face environments. The same issues were detected in this study as well. However, apart from that, this study reveals that students' dissatisfaction differs depending on their motivation. By means of this study, it is aimed to introduce a system that can be used especially while developing smart distance education systems. 


\section{SUGGESTIONS}

$>$ It is concluded that it would be beneficial if distance education systems were designed considering socio-psychological variables as well as technical factors.

$>$ Considering the characteristics of individuals studying in distance education, distance education systems can be designed by adding socio-economic factors and the perspective of new technological devices to qualitative data obtained.

> By using the data obtained, the relationship between success and motivation, satisfaction and online experience through experimental studies can be identified.

\section{BIODATA and CONTACT ADDRESSES Of AUTHORS}

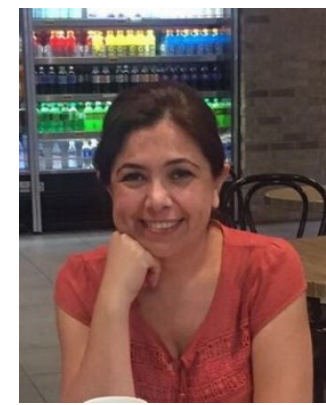

Dr. Ozlem CAKIR

Department of Computer Education and Instructional Technology

Faculty of Educational Sciences, Ankara University, 06500, Ankara, Turkey

Phone: +903123633350/3210

E-mail: ozlemcak@yahoo.com

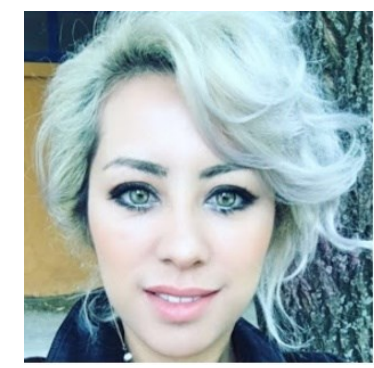

Tugra KARADEMIR is the research assistant in the Department of Computer Education and Instructional Technology, Faculty of Education, Ankara University. She received her master degree in Computer Education and Instructional Technology from Ankara University (2012) and she is pursuing her Ph.D. studies at Ankara University. Her research interests are in digital learning materials, programming, robotics and mobile learning.

\section{Tugra KARADEMIR}

Department of Computer Education and Instructional Technology

Faculty of Educational Sciences, Ankara University, 06500, Ankara, Turkey

Phone: +903123633350 / 7106

E-mail: tugra1986@gmail.com

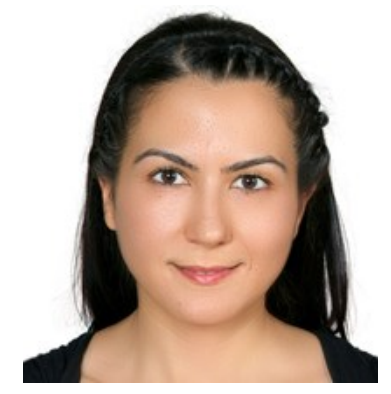

Dr. Funda ERDOGDU received her master and PHD degree in Department of Computer Education and Instructional Technologies Program at Ankara University. Her research areas include adaptive learning, adaptive motivation strategy, distance education, social network, PISA research.

Department of Computer Education and Instructional Technology Faculty of Education, Dumlupinar University, 43100, Kutahya, Turkey Phone: +902742652031 / 4580

E-mail: funda.erdogdu@dpu.edu.tr 


\section{REFERENCES}

Althaus, S. L. (1997). Computer-mediated communication in the university classroom: An experiment with on-line discussions. Communication Education, 46(3), 158-174.

Arbaugh, J. B. 2000. How classroom environment and student engagement affect learning in Internet-based MBA courses. Business Communication Quarterly, 63 (4), 9-26.

Artino, A.R. (2008). Motivational beliefs and perceptions of instructional quality: predicting satisfaction with online training. Journal of Computer Assisted Learning, 24(3), 260270.

Balaban-Sali, J. (2008). Designing motivational learning systems in distance education. Turkish Online Journal of Distance Education, 9(3), 149-161.

Bambara, C. S., Harbour, C. P., Davies, T. G., \& Athey, S. (2009). Delicate engagement: The lived experience of community college students enrolled in high-risk online courses. Community College Review, 36(3), 219-238.

Battalio, J. (2007). Interaction online: A reevaluation. Quarterly Review of Distance Education, 8(4), 339-352.

Belcheir, M., \& Cucek, M. (2002). Faculty perceptions of teaching distance education courses. Research Report: 2002. Boise, ID: Boise State University. (ERIC Document Reproduction Service No. ED 480925).

Bourne, J. and Moore, J. C. (2003). Elements of quality online education: into the mainstream. Elements of Quality Online Education: Into the Mainstream. Edited by John Bourne and Janet C. Moore. Volume 5 in the Sloan-C Series.

Bouhnik, D. \& Marcus, T. (2006). Interaction in distance-learningcourses. Journal of The American Society Information Science and Technology, 57(3), 299-305.

Brinkerhoff, J. \& Koroghlanian, C.M. (2005). Student computer skills and attitudes toward internet-delivered instruction: An assessment of stability over time and place. Journal of Educational Computing Research, 32, 27-56.

Brophy, J. E. (2010). Motivating students to learn (3rd ed.). New York: Routledge.

Bork, R. H. \& Z. Rucks-Ahidiana. (2013). Role ambiguity in online courses: An analysis of student and instructor expectations (CCRC Working Paper No. 64). New York: Columbia University, Teachers College, Community College Research Center. Retrieved September 10, 2016 from https://ccrc.tc.columbia.edu/media/k2/ attachments/roleambiguity-in-online-courses.pdf

Buyukozturk, S., Akgun, O. E., Ozkahveci, O., Demirel, F. (2004). Gudulenme ve ogrenme stratejileri olceginin Turkce formunun gecerlik ve guvenirlik calismasi [The Validity and Reliability Study of the Turkish Version of the Motivated Strategies for Learning Questionnaire]. Kuram ve Uygulamada Egitim Bilim/eri, 4(2), 207-239.

Buyukozturk, S. (2009). Sosyal bilim/er icin veri analizi el kitabı [The handbook of data analysis for social sciences]. (10.Baski). Ankara: Pegem Akademi.

Cakir, 0. (2012). The development of online students' satisfaction scale. Energy Education Science and Technology Part B: Social and Educational Studies, Special Issue-1, 4(5): 947-950.

Cakir, O. (2014). The Factors that Affect Online Learners' Satisfaction. Anthropologist, 17(3): 895-902.

Chaiprasurt, C. \& Esichaikul, v. (2013). Enhancing motivation in online courses with mobile communication tool support: a comparative study. The International Review of Research in Open and Distance Learning, 14, 377-401.

Chang, S.C. and Tung, F.C. (2008). An empirical investigation of students' behavioural intentions to use the online learning course websites. British Journal of Educational Technology, 39 (1),71-83. 
Chu, R. J. \& Chu, A. Z. (2010). Multi-level analysis of peer support, Internet self-efficacy and elearning outcomes: The contextual effects of collectivism and group potency. Computer \& Education, 55, 145-154.

Cornell, R. ve Martin, B. L. (1997). The role of motivation in web-based instruction. (Ed. Badrul H.Khan) Web-Based Instruction. New Jersey. USA: Educational Technology Publications.

Cookson, P. S. (1989). Research on learners and learning in distance education. The American Journal of Distance Education, 2 (1), 22-34.

Creswell J. W. (2013). Qualitative inquiry and research design: Choosing among five approaches. Thousand Oaks, CA: Sage.

Dick, W., Carey, L. \& Carey, J.O. (2005). The Systematic Design Of Instruction. Boston, MA: Pearson/Allyn and Bacon.

Distance learning, (2016). In encyclopedia Britannica. Retrieved October 15, 2016 from http://global.britannica.com/topic/distance-learning

Drennan, J., Kennedy, J. \& Pisarski, A. (2005). Factors Affecting Student Attitudes Toward Flexible Online Learning in Management Education. Journal of Educational Research, 98 (6), 331-338.

Eastin, M.S. \& LaRose, R. (2000). Internet self-efficacy and the psychology of the digital divide. Journal of Computer Mediated Communication, 6 (1).

El Mansour, B., and D. M. Mupinga. 2007. Students' positive and negative experiences in hybrid and online classes. College Student Journal, 41 (1), 242-248.

Field, A. (2005). Discovering statistics using SPSS (2nd ed.). London: Sage.

Giesbers, B., Rienties, B., Tempelaar, D. T., \& Gijselaers, W. H. (2013). Investigating the relations between motivation, tool use, participation, and performance in an E-learning course using web-videoconferencing. Computers in Human Behavior, 29(1), 285-292.

Gaddis, B., Napierkowsk, H., Guzman, N., \& Muth, R. (2000). A comparison of collaborative learning and audience awareness in two computers-mediated writing environments. Association for Educational Communications and Technology, 140-147. Retrieved January 05, 2016 from http:/ files.eric.ed.gov/fulltext/ED455771.pdf

Garrison, D. (1990). An analysisandevaluation of audio teleconferencing to facilitate education at a distance. AmericanJournal of DistanceEducation, 4(3), 13-24.

Gujarati, D.N. (1995). Basic Econometrics, 3rd Edition. New York: McGraw-Hill. ISBN 0-07025214-9.

Hannafin, J. J., \& Cole, D. D. (1983). An analysis of why students select introductory high school computer coursework. Educational Technology, 23(4), 26-29.

Harandi, S.R. (2015). Effects of e-learning on students' motivation. 3rd International Conference on Leadership, Technology and Innovation Management. Procedia-Social and Behavioral Sciences, 181, 423-430.

Hong, K. S. (2002). Relationships between students' and instructional variables with satisfaction and learning from a Web-based course. Internet and Higher Education, 5, 267-281.

Ilgaz, H. (2008). Uzaktan Egitimde Teknoloji Kabulunun ve Topluluk Hissinin Ogrenen Memnuniyetine Katkısı [The Contribution Of Technology Acceptance and Communıty Feeling To Learner Satisfaction In Distance Education]. (Master's dissertation) Hacettepe University Graduate School of Science, Ankara, Turkey. Available from the Council of Higher Education, National Dissertation Center, Dissertation ID: 244862.

Jeamu, L., Kim, Y., \& Lee, Y. (2008). A web-based program to motivate underachievers learning number sense. International Journal of Instructional Media, 35(2), 185-194.

Jones, P., Packham, G., Miller, C., \& Jones, A. (2004). An initial evaluation of student withdrawals within an elearning environment: The case of e-college Wales. Electronic Journal on e-Learning, 2 (1), 113-120. 
Karatas, S. ve Ustundag, M.T. (2008). Gazi Universitesi Uzaktan Egitim Programi Ogrencilerinin Internet Temelli Uzaktan Egitim Doyumlari ile Demografik Ozellikleri Arasindaki Iliski [The Relationship between Students' Internet-Based Distance Education Satisfactions and Demographical Properties in Gazi University Distance Education Program]. Yuzuncu Yıl Universitesi, Egitim Fakultesi Dergisi, V(II), 62-73.

Kesim, E. (2015). The Importance of Distance Education Experts in the Organizational Development Process of Distance Education Institutions: A Theoretical Evaluation. In. G. Eby \&amp; T.V. Yuzer (Eds.), Identification, Evaluation and Perceptions of Distance Education Experts (pp.73-88). Hershey, PA.: Information Science Reference.

Kransow, J. (2013). Faculty leadership in online education: Structuring courses to impact student satisfaction and persistence. MERLOT Journal of Online Learning and Teaching, 9(1), 131-139.

Jaggards, S. S. (2014). Choosing Between Online and Face-to-Face Courses: Community College Student Voices. American Journal of Distance Education, 28(1).

Mertler, C. A., \& Vannatta, R. A. (2005). Multiple regression. In Advanced and multivariate statistical methods (Third ed). Glendale, CA: Pyrczak Publishing.

Kaupp, R. (2012). Online penalty: The impact of online instruction on the Latino-White achievement gap. Journal of Applied Research in the Community College, 12(2), 1-9.

Keller, J. M. and Suzuki, K. 2004. Learner motivation and e-learning design: A multinationally validated process. Journal of Educational Media, 29(3): 229-239.

Kitchen, D., \& McDougall, D. (1998). Collaborative learning on the Internet. Journal of Educational Technology Systems, 27(3), 245.

Kranzow, J. (2013). Faculty leadership in online education: Structuring courses to impact student satisfaction and persistence. MERLOT Journal of Online Learning and Teaching, 9(1), 131-139.

Kuo, Y.C, Walker, A.E., Belland, B.R \& Schroder, K.E.E. (2013). A Predictive Study of Student Satisfaction in Online Education Programs. International Review of Reseach in Open and Distance Learning, 14(1), 16-39.

Liaw, S.S. (2008). Investigating students' perceived satisfaction, behavioral intention, and effectiveness of e-learning: A case study of the Blackboard system. Computers \& Education, 51, 864-873.

Lim, C. K. (2001). Computer self-efficacy, academic self-concept, and other predictors of satisfaction and future participation of adult distance learners. American Journal of Distance Education, 15(2), 41-51.

Martin, A.J. (2001). The Student Motivation Scale: A Tool for Measuring and Enhancing Motivation. Australian Journal of Guidance and Counseling, 11, 1-20.

Mitchell, T. J. F., Chen, S. Y., \& Macredie, R. D. (2005). The relationship between web enjoyment and student perceptions and learning using a web-based tutorial. Learning, Media and Technology, 30 (1), 27-40.

Muilenburg, L. Y., \& Berge, Z. L. (2005). Student barriers to online learning: A factor analytic study. Distance Education, 26(1), 29-48.

Moore, M. G. \& Kearsley, G. (1996). Distance education a systems view (Belmont, CA, Wadsworth Publishing Co.).

Morris, L. V., Finnegan, C., \& Wu, S. (2005). Tracking student behavior, persistence, and achievement in online courses. The Internet and Higher Education, 8(3), 221-231.

Palmer, S. R. \& Holt, D. M. (2009). Examining Student Satisfaction with Wholly Online Learning. Journal of Computer Assisted Learning, 25 (2), 101-113.

Pintrich, PR., Smith, D., Garcia, T. \& McKeachie, WJ. (1993). Reliability and predictive validity of the Motivated Strategies for Learning Questionnaire (MSLQ). Educational and Psychological Measurement. 53, 801-13. 
Rattan, A., Good, C., Dweck, C. (2012), "It's OK- Not everyone can be good at math": Instructors with an entity theory comfort (and demotivate) students. Journal of Experimental Social Psychology, 48, 731-737.

Sahin, I. (2007). Predicting student satisfaction in distance education and learning environments. Turkish Online Journal of Distance Education, 8(2). 113-119.

Sahin, I. \& Shelley, M. (2008). Considering Students' Perceptions: The Distance Education Student Satisfaction Model. Educational Technology \&Society, 11(3), 216-223.

Soon, KH., Sook, KI., Jung, CW. \& Im, KM. (2000). The effects of Internet-based distance learning in nursing. Computers in Nursing, 18(1), 19-25.

Sun, P.C, Tsai, R.J. Finger, G., Chend, Y-Y.\& Yeha, D. (2008). What drives a successful eLearning? An empirical investigation of the critical factors influencing learner satisfaction. Computers \& Education, 50 (4), 1183-1202.

Simsek, N. (2012). Uzaktan egitimde kalite gostergeleri ve teknoloji temelli uzaktan egitimin bu gostergeler acisindan degerlendirilmesi [Quality Indicators in Distant Education and the Assessment of Technology-Based Distant Education according to These Indicators]. Egitim Bilim/eri ve Uygulama, 11 (21), 1-24.

Strachota, E.M. (2003). Student satisfaction in online courses: An analysis of the impact of learner-content, learner-instructor, learner-learner and learner-teacher interaction. Dissertation Abstracts International, 64 (8), 2746. Key: citeulike: 1029163.

Swan, K. (2001). Virtual interaction: Design factor saffecting student satisfaction and perceived learning in asynchronous online courses. Distance Education, 22(2), 306-331.

Tavsancil, E. ve Aslan, E. (2001). Icerik analizi ve uygulama ornekleri [Content analysis and application examples]. İstanbul: Epsilon Yayıncılık.

Visser, L. (1998). The development of motivational communication in distance education support. Report for the Educational Technology Department (Twente, University of Twente, Enscede, The Netherlands). Retrieved June 05, 2016 from http://www.learndev.org/People/LyaVisser/DevMotCommInDE.pdf

Visser, L., Plomp, T., Amirault, R. J., \& Kuiper, W. (2002). Motivating students at a distance: The case of an international audience. Educational Technology Research and Development, 50(2), 94-110.

Yukselturk, E., \& Yildirim, Z. (2008). Investigation of interaction, online support, course structure and flexibility as the contributing factors to students' satisfaction in an online certificate program. Educational Technology \& Society, 11(4), 51-65.

Xie, K., DeBacker, T.K., \& Ferguson, C. (2006). Extending the traditional classroom through online discussion: The role of student motivation, Journal of Educational Computing Research, 34(1), 68-78.

Wagner, R., Werner, J. M., \& Schramm, R. (2002). An evaluation of student satisfaction with distance learning courses. Proceedings of the 18th Annual Conference on Distance Teaching and Learning (2002, August). (pp. 419-423). Madison: WS. 